\title{
Standardization of educational system: impact on the state of science education in South African
}

Keywords: basic education, curriculum, economic growth, national education, educational system, pass rate, science study, educational problems

Abbreviations: NCS, national curriculum statements; DBE, department of basic education; NSC, national senior certificate; CAPS, curriculum and assessment policy statements; ANA, annual national assessments; TIMSS, trends in international mathematics and science study

\section{Introduction}

Early next year, 2018, South Africa's National Senior Certificate (NSC) matric results fanfare will take place. Many issues will be raised by the Department of Basic Education (DBE) as to why the learners of 2017 pass rate, good or bad, needs to be celebrated. As a yearly norm, some critical concerns of many observers will be put under the carpet until at least another year.

\section{The issues around the current educational system}

In this current scientific and technological world, quality science education drives a country's economic growth and competitiveness. Through appropriate curriculum and policy implementations, transformation and innovation are attained to improve quality of life of citizens. Notably, the educational system is retaining its stability after the move from National Education (NATED 550), through Curriculum 2005 (C2005) to National Curriculum Statements (NCS) and finally to the Curriculum and Assessment Policy Statements (CAPS). Behind genuine success stories from the educational system (Grade R-12), international and national assessments on science learners' academic performances have indicated perennial underperformances. Based on three reliable indicators (1) The Annual National Assessments (ANA) results from 2012-2016 point to continued poor performances; (2) the Trends in International Mathematics and Science Study (TIMSS) placed South African learners below the international centre point, and (3) the performance of matric results has not been good in critical subjects like physical sciences (combination of physics and chemistry) which has one of the most failed learners. Many general factors attributed to learner under-performances include high levels of poverty, poorly scientific resourced schools, early retirement, teacher shortages, misinterpretation of curriculum, poor subject knowledge, and etc. All these factors fall under infrastructure and teacher-related issues. There are department related underlining factors which do not often feature in secular domain. Although some of the DBE policy issues are not intentional, they often initiate the educational problemsthree of which this article intends to highlight.

\section{Policies injections to favour marginalized learners}

According to DBE policy, the minimum pass requirement for elective subjects including physical sciences drops to $30 \%$ from $40 \%$. The state's intention behind this policy is to ensure that majority of learners, mostly previously disadvantaged, who achieve $30 \%$ (which is fail), are not compared to repeat or drop out or to be considered to

\author{
Volume I Issue 6 - 2017
}

\author{
Charles Cobbinahs \\ Post Doctoral Fellow, University of Fort Hare, South Africa
}

Correspondence: Charles Cobbinah, Post Doctoral Fellow, University of Fort Hare, South Africa,

Tel 043704762I,Email ccobbinah@ufh.ac.za

Received: December 06, 2017 | Published: December 14, 2017

have failed matric. In physical sciences, the pass rates for the years 2014,2015 and 2016 stood at $61.5 \% ; 58.6 \%$ and $62.0 \%$ respectively (if $30 \%$ and above is considered). However, the results stay at $36.9 \%$; $36.1 \%$ and $39.5 \%$ respectively if pass rate is raised to $40 \%$ and above. One prominent question is, why too many learners are attaining just this benchmark or below it? It is important to consider the side effect of this policy. Saliently, it has succeeded in building a culture of contentment in low marks attainment since what $40 \%$ and above can do, $30 \%$ is believed to do it better. The variable 'negative attitude' which relate to underachievement is established towards science pedagogy. Even learners who obtained $28 \%$ in science examinations are hopeful they could be condoned by adjusting their marks to $30 \%$ to mean pass. It has influenced confidence and amount of effort potential learners could invest in their science studies.

Another policy which has attracted much debate is the 'progressed learners' one. Despite the $30 \%$ pass mark, a learner who could not meet the promotion requirement for the second time be progressed to the next grade. The state's intention of progression is to ensure that a learner may not spend more than four years in any particular phase. This is also in the best interest of the learner but not the educational system. Without this policy protection, many learners are feared to drop out of the system due to over-repetition or find themselves in a grade with under-age learners where they may face social and emotional challenges. Reddy, Hannan, and Zuze-Wilcox (2016) argued that since failed learners lack prerequisite knowledge to cope with the next grade, such learners may rather become "despondent, frustrated and be dropping out... and creates added pressure for teachers". This implies that the same problem the policy sought to resolve may eventually surface but with side effects. Due to much surety, although there are genuine failures, some learners voluntarily fail the critical subjects to await the policy roll out. A battling learner compromises a year to escape the pressures of having to improve performances and remain optimistic about finishing matric. Even those learners, who could improve from the first failure, decide to float with the policy. In most cases, the progressed learners, with nothing to aspire, become the most discouraged and problematic learners in the classrooms and schools. Their conduct undermines the drive to pass sciences through hard work, set precedent in discouraging potential learners and impact on overall internal and external school results. 
In this year, 2017, at Grade 12 level, modulation policy was emphasized to curb some of the progressed leaner effects (as 108742 wrote NSC in 2016). A complied but battling progressed learner gets multiple opportunities to write the NSC. The idea is to make it flexible once again for the learner to take few subjects at own pace. It means if learners are failing to progress, then let progress and modulate them to fail. What is the guarantee that a weak but overgrown physical science learner pampered by the educational system will accept to write matric twice or thrice and pass to attain the NSC? Many weak learners may be ushered out of the system, but such an approach has implications for the most failed subjects such as physical sciences required for scarce skills in the country. Many learners may not offer this subject and some schools may discontinue it.

\section{Conclusion}

In South Africa, although internationally accepted educational policies are practiced, the intensity and the skew ness towards previously disadvantaged learners' gap bridging, appears to make the implementation processes undermine the essence of quality science education for all enrolled learners. Often at times, the educational system is standardized to accommodate all learners instead of all learners meeting the fixed educational targets. Hence, lacking scientific knowledge-based economy via transformative pedagogy is becoming societal concern. Rendering sciences as 'invisibilized dirty subjects' and their teaching as an 'invisibilized dirty work'.

\section{Acknowledgements}

None.

\section{Conflict of interest}

The authors declare that they have no conflict of interest. 